\title{
Measurement science and education in the Internet era
}

The Internet has fundamentally altered the world in all social and economic areas within a historically short period of time. Metrology and Measurement Science have been playing an important role in our society for more than 5000 years yet the field has been significantly changed during the last 30 years, not only due to the influence of new Internet technologies but also to the influence of micro- and nano-technologies.

Examples of where these new developments express themselves are through the following trends in Metrology and Measurement Science:

- Supplementation of traditional teaching and education concepts with modern Internet-based learning techniques (e.g., multimedia courseware "Metromedia-Online" (http://www.metromediaonline.com), NPL's dimensional metrology e-training course (http://www.npl.co.uk/e_training/dimensional_metrology/)).

- Replacement of classical instrument-specific education and further training in the measuring equipment industry through Internet-based solutions.

- Internet-based operating and maintenance instructions in the field of measurement and testing technology.

- Internet-based methods and tools for static and dynamic visualisation of complex, theoretical interrelationships in metrology and measurement science.

- Decentralised and time-independent learning and communication between teacher and learners as well as between learners.

- Efficient and fast knowledge gain in metrology and measurement science through virtual laboratories and virtual instrumentation (e.g., NI Edu- cational Laboratory Virtual Instrumentation Suite (NI ELVIS), http://www.ni.com).

- Simplified worldwide exchange regarding metrological terms and standards as well as acceleration of the standardisation process in metrology and measurement science (e.g. EUKOM (European Training for Coordinate Metrology), http://www.eukom.com).

- Internet-based methods for traceability and relation to known standards.

- Remote calibration (Internet calibration services offered by UK's National Physical Laboratory (NPL), http://www.npl.co.uk/electromagnetic/ ical.html).

- Remote control of sensors and measuring systems via the Internet.

- Remote maintenance and diagnosis (e.g., remote diagnosis or software updates performed by Carl Zeiss for example for UNIVERSARIUM Mark IX projectors).

- Increasing interconnection of sensors and measuring systems (e.g., GigE (Gigabit Ethernet), http://en.wikipedia.org/wiki/GigE).

- Multisensor systems.

- Broad applications of sensor systems in our society, such as toll collect systems, vision sensors for monitoring and surveillance, the European Installation Bus (EIB) for building automation, driver assistance systems in automotive engineering, sensor-controlled facility management and smart sensors.

This special issue of "Measurement" contains a selection of papers presented at the JOINT TC1TC7 IMEKO International Symposium on "Measurement Science and Education in the Internet Era", Ilmenau, Germany, 21-24 September 2005. 
The symposium programme comprised 4 keynote presentations, 2 tutorials, 13 poster presentations and 44 oral presentations, with topics related to education in measurement science and industrial applications. Various authors had been invited to submit an extended version of their symposium paper to this Journal. The result is a special issue with 13 papers highlighting some of the key aspects listed above, illustrating the fascinating and influential implications of the Internet on Measurement Science and the impact on teaching methodologies, international standardisation and design concepts.

The papers by Conrad, Morawski, Oliveira, Regtien, and Tiberghien deal explicitly with educational issues. Mari, Ruhm, and Velychko discuss specific (global) metrological issues. The authors of the remaining papers highlight specific industrial aspects in a modern context: Belotti on remote operations, Czaja on fault diagnosis, Rietveld on Internet based maintenance and Töpfer and Kühn on automatic inspection of microstructures.

We hope the readers will enjoy this issue and get inspired by this pallet of articles to respond with submissions to the Journal about their own experiences in this field.

Paul P.L. Regtien

G. Linss

Guest editors

Available online 26 October 2006 